\title{
Humik Asit Uygulama Zamanı ve Dozlarının Kışlık Kolzada Verim ve Verim Öğelerine Etkileri
}

\author{
*Mehtap GÜRSOY' ${ }^{*}$ Farzad NOFOUZi ${ }^{2}$ Dilek BAŞALMA ${ }^{2}$
}

\author{
${ }^{1}$ Aksaray Üniversitesi, Güzelyurt Meslek Yüksekokulu, Aksaray \\ ${ }^{2}$ Ankara Üniversitesi, Ziraat Fakültesi, Tarla Bitkileri Bölümü, Ankara \\ *Sorumlu yazar e-posta (Corresponding author e-mail): mehtapgrsoy@gmail.com
}

\section{Öz}

Bu çalışmanın amacı; kışıı kolzaya farklı zamanlarda ve değişik dozlarda humik asit uygulamalarının verim ve verim öğelerine etkilerini belirlemektir. Ankara koşullarında 2013-2014 yılında Tesadüf Bloklarında Bölünmüş Parseller deneme desenine göre üç tekerrürlü olarak kurulan denemede Bristol çeşidi kullanılmıştır. Humik asit dozları olarak (0, 250, 500, $1000 \mathrm{ml} / \mathrm{da}) 4$ farklı doz uygulanmıştır. Humik asit uygulama zamanları olarak; çıkış, 6-8 yapraklı, sapa kalkma, çiçeklenme dönemleri belirlenmiştir. Araştırmada; bitki boyu, ana sapa bağlı yan dal sayısı, ana saptaki kapsül sayısı, kapsülde tohum sayısı, bin tohum ağırlığı ve tohum verimine ait ölçüm ve gözlemler yapılmıştır. Araştırmanın sonucunda ele alınan özelliklerin tamamında humik asit uygulama zamanları ve dozları arasındaki farklılıklar istatistiki açıdan önemli bulunmuştur. En yüksek değerler, bitki boyunda $118.60 \mathrm{~cm}$ ile 6-8 yapraklı dönemde ve $250 \mathrm{ml} /$ da humik asit uygulamasından, ana saptaki kapsül sayısı 30.77 adet ile sapa kalkma ve 500 ml/da humik asit dozundan, bin tohum ağırlığı 3.68 g ile 6-8 yapraklı dönemde ile kontrol uygulamasından ve tohum verimi değeri de 238.40 kg/da ile 6-8 yapraklı dönemde ve $250 \mathrm{ml} /$ da uygulamalarından elde edilmiştir. Bu çalışmada genel olarak, humik asit dozlarından 250 ve $500 \mathrm{ml} / \mathrm{da}$ uygulamalarının ve uygulama zamanı olarak da 6-8 yapraklı ve sapa kalkma dönemlerinin incelenen özellikler bakımından daha iyi sonuçlar verdiği gözlenmiştir.

Anahtar Kelimeler: Kolza, humik asit, uygulama dozu, uygulama zamanı, tohum verimi

\section{Effects Humic Acid Application at Different Stages of Growth on Yield and Yield Components of Winter Rapeseed Crops}

\begin{abstract}
The purpose of this study was to evaluate effects of durations of different doses of humic acids on yield and yield components of winter rapeseed. The study was carried out at Ankara, the experiment was established as split block design with three replications during 2013-2014. Cv. Bristol was used in the experiment. Humic acid doses of 0, 250, 500, $1000 \mathrm{ml} / \mathrm{da}$ were applied. Humic acid was applied at 6-8 leaves stage, bolting and flowering stages. In the study; plant height, number of branches on main stem, number of capsules per main stem, number of seeds per capsule, one thousand seed weight and seed yield were the parameters for which observations were taken. In all of the parameters, discussed in the results of the study statistically significant differences were noted between humic acid application stages and dose. The maximum plant height of $118.60 \mathrm{~cm}$ was noted at humic acid application at $6-8$ leaf stage using $250 \mathrm{ml} / \mathrm{da}$. The maximum number of 30.77 capsules were noted on main stem at when humic acid was applied at bolting stage using $500 \mathrm{ml} / \mathrm{da}$ humic acid. Thousand seed weight of $3.68 \mathrm{~g}$ was noted at $6-8$ leaf stage on control treatment. Maximum seed yield $(238.40 \mathrm{~kg} / \mathrm{da}$ was noted at $250 \mathrm{ml} / \mathrm{da}$ humic acid application at $6-8$ leaf stage. Generally, humic acid doses of 250 and $500 \mathrm{ml} / \mathrm{da}$ were more productive on all traits after their application at 6-8 leaves stage and bolting stage that resulted in better yields.
\end{abstract}

Keywords: Rapeseed, humic acid, dosage, application time, seed yield 


\section{Giriş}

$\mathrm{K}$ olza (Brassica napus ssp. oleifera L.) oleik asitçe zengin, Omega-3 yağ grubu içerisinde yer alan, yazlık ve kışlık çeşitleri olan, tohumunda \%40-50 ham yağ içeren önemli bir yağ bitkisidir. Ayrıca birim alandan yüksek tohum verimi $(342 \mathrm{~kg} / \mathrm{da}$ ) alınan bir bitkidir (Anonim 2015). Aynı zamanda yüksek yağ oranı (\%4550 ) elde edilmesi, ekiminden hasadına kadar bütün yetiştirme tekniğinin mekanizasyona uygun olması, ilkbaharda hızlı gelişerek yabancı otların gelişimini engellemesi ve kendisinden sonraki ürüne temiz toprak bırakması gibi özellikleri ile de oldukça avantajlı bir bitki durumundadır (Beğbağa ve Öztürk, 2008).

Yağlı tohumlu bitkiler arasında, Türkiye'nin ekolojik şartlarına uyumlu bitkilerden biri de kolzadır. Kolza tohumundan elde edilen yağ yemeklik yağ olarak kullanılmakla birlikte, sabun sanayiinde, boya sanayisinde, derileri yumuşatmada, süetlere elastikiyet vermede, çeşitli motorlarda hidrolik yağ olarak ve özellikle Avrupa ülkelerinde biyodizel yapımında önemli oranlarda kullanılmaktadır (Anğın ve Vurarak 2012).

Dünya nüfusunun hızlı artışına karşılık tarım yapılan arazi alanlarının sınırlı kalması hatta konut, turizm, sanayi gibi çeşitli nedenlerle tarım arazilerinin azalması söz konusudur. Sınırlı olan tarım arazilerinde en yüksek birim alan veriminin elde edilmesi önemlidir. Bitkilerin ilk gelişme devrelerinde kök ve toprak üstü organlarının gelişimlerini hızlı bir şekilde tamamlamaları halinde olumsuz çevre şartlarından daha az etkilendikleri ortaya konmuştur (Day ve ark. 2011). Bitkisel üretimde, verimliliğin artırılması amacıyla kimyasal ve çiftlik gübrelerinin yanı sıra organik, organomineral, toprak düzenleyiciler ve mikrobiyal gübrelerin kullanım oranları da artmıştır (Asri ve ark. 2011). Özellikle humikasitin bitki biyokütlesini artırdığı, etkinin kök gelişiminde daha fazla olduğu belirlenmiştir (Sözüdoğru ve ark. 1996). Humik maddeler toprakta geniş bir pH aralığında tampon özelliği gösterir ve pek çok mikro besin elementini bitkiler için alınabilir hale getirir (Karaman ve ark. 2012). Humik asit uygulaması ile toprağın havalanması ve su tutması iyileştirilirken, aynı zamanda toprak mikroorganizmalarının gelişim ve çoğalması sağlanmaktadır. Bununla beraber bitkilerin stres koşullarına, hastalık ve zararılılara dayanıklıı̆ının artıııdığı ifade edilmektedir (İçel 2005).

Day ve ark. (2011) Ankara koşullarında humik asit uygulama zamanı ve dozlarının ayçiçeğinde verim, verim öğeleri ve yağ oranına etkisini inceledikleri çalışmalarında; 3 farkı uygulama zamanı olarak ekimden önce toprağa, çıkıştan sonra 4-5 yapraklı devre ve minyatür tabla oluşum dönemlerini ve humik asidin de (kontrol, 6, 12 ve $18 \mathrm{~g} / \mathrm{da}$ ) 4 dozunu kullanmışlardır. En yüksek bitki boyunu 133.7 $\mathrm{cm}$ ile minyatür tabla oluşum döneminde yapılan $6 \mathrm{~g} / \mathrm{da}$ humik asit uygulamasında, en yüksek yağ oranını \%53.6 ile yine aynı zamanda uygulanan $18 \mathrm{~g} / \mathrm{da}$ 'lık humik asit dozunda belirlemişlerdir. Araştırıcılar gelişme dönemleri ilerledikçe humik asit uygulamasının yağ oranını artırdığını saptamışlardır. En yüksek tane veriminin ise $410 \mathrm{~kg} / \mathrm{da}$ ile ekimden önce toprağa uygulanan $18 \mathrm{~g} / \mathrm{da}$ humik asit dozundan elde ettiklerini bildirmişlerdir. Ergönül (2011) ayçiçeği çeşitlerine uyguladığı humik asit ve leonarditin verim ve verim öğeleri üzerine etkilerini incelediği çalışmasında ayçiçeği çeşitlerinde kullanılan farklı gübre uygulamalarının verim ve birçok verim öğesi üzerine etkilerini istatistiksel bakımdan önemli bulmuştur. En geniş tabla çapını leonardit + gübre uygulaması yapılan parselde $19.43 \mathrm{~cm}$ olarak belirlemiştir. Bitki sayısı ise en fazla hümik asit uygulamasında 13.21 adet olarak tespit edilmiştir. En yüksek tohum verim değerini leonardit + gübre uygulamasında 198.61 kg/da olarak kaydetmiştir. Ayçiçeği bitkisinin tarımında organik gübre uygulamalarının bitkinin verim ve verim öğelerinde artış sağladığı, toprağın kimyasal ve fiziksel durumunu iyileştirdiği sonucuna varmıştır.

Bu çalışmanın amacı, Ankara koşullarında farklı gelişme dönemlerinde uygulanan, değişik humik asit dozlarının kolzanın verim ve verim öğelerine etkisini belirlemektir.

\section{Materyal ve Yöntem}

Araştırma 2013-2014 yıllarında Ankara Üniversitesi, Ziraat Fakültesi, Tarla Bitkileri Bölümü araştırma tarlasında yürütülmüştür. Bristol kışlık kolza çeşidi materyal olarak kullanılmışıı. Kolzanın yetişme döneminde uzun yıllar sıcaklık ortalaması $9.56^{\circ} \mathrm{C}$ iken Eylül 2013Haziran 2014 ayları sıcaklık ortalaması $10.88^{\circ} \mathrm{C}$ dir. Uzun yıllar yağış ortalaması $37.23 \mathrm{~mm}$ iken denemenin yürütüldüğü dönemlerde ortalama yağış $27.21 \mathrm{~mm}$ olarak gerçekleşmiştir. Deneme döneminde sıcaklık ortalaması uzun yıllar değerlerinden yüksek, ortalama yağış ise düşük olmuştur. Denemenin yürütüldüğü arazinin toprakları tınlı kumlu bir tekstüre sahip olup, yapılan toprak analizleri sonucu, toplam N \%'si 

of Winter Rapeseed Crops"

0.11, alınabilir P 4.04 ppm, alınabilir K 423.4 ppm ve organik madde $\% 2.14$ olarak saptanmıştır.

Araştırma, Tesadüf Bloklarında Bölünmüş Parseller deneme desenine göre üç tekerrürlü olarak kurulmuştur. Ekim tarihi 16 Eylül 2013'tür. Denemede Bristol kolza çeşidine uygulanan dört humik asit dozu $(0,250,500,1000 \mathrm{ml} / \mathrm{da})$ ve farklı uygulama zamanları (çıkış, 6-8 yaprakı, sapa kalkma, çiçeklenme) ele alınmıştır. Denemede uygulama zamanları ana parselleri oluşturmuştur. Alt parsellerden her biri $5 \mathrm{~m}$ uzunluğunda ve 4 sıradan oluşmuştur. Sıra araları ise $30 \mathrm{~cm}$ 'dir. Bitkiler ekimden sonra 20$25 \mathrm{~cm}$ boylandığında 1 . çapa, yaklaşık bir ay sonra 2.çapa yapılmıştır. Sulama, gübreleme ve tüm bakım işlemleri gerektiği zamanlarda uygulanmıştır. Hasat olgunluğuna gelen parsellerde tesadüfi seçilen 10 bitkide bitki boyu, ana sapa bağlı yan dal sayısı, ana saptaki kapsül sayısı, kapsülde tohum sayısı ölçümleri yapılmıştır. Her parselden elde edilen tohumların tartılması ile bin tohum ağırlığı değerleri ve tohum verimleri kaydedilmiştir.

Elde edilen verilerle Mstat-C istatistiki analiz yöntemine göre varyans analizleri yapılmış, uygulamalar arasındaki farklılıkların önem düzeyleri Duncan testi ile değerlendirilmiştir (Düzgüneş ve ark. 1987).

\section{Bulgular ve Tartışma}

Ankara koşullarında kışlık kolzada farklı humik asit uygulama zamanı ve dozlarının tohum verimi ve verim öğeleri üzerine etkilerine ilişkin varyans analiz sonuçları Çizelge 1 'de sunulmuştur. Çizelge 1'de görüldüğü gibi; bitki boyu, ana sapa bağlı yan dal sayısı, ana saptaki kapsül sayısı, kapsülde tohum sayısı, bin tohum ağırlığı ve tohum verimleri üzerine humik asit uygulama zamanı $\mathrm{x}$ uygulama dozları interaksiyonu istatistiki olarak \%1 düzeyinde önemli bulunmuştur. İncelenen özelliklere ilişkin humik asit uygulama zamanı ve uygulama dozlarına ait ortalama değerler ve Duncan grupları Çizelge 2'de verilmiştir.

Bitki boylarına ait ortalama değerler incelendiğinde; en yüksek bitki boyu $118.60 \mathrm{~cm}$ ile 6-8 yapraklı dönemde yapılan $250 \mathrm{ml} / \mathrm{da}$ humik asit dozundan elde edilmiştir. En düşük bitki boyu ise $91.72 \mathrm{~cm}$ ile çiçeklenme döneminde yapılan $500 \mathrm{ml} / \mathrm{da}$ humik asit dozunda ölçülmüştür. Humik asit uygulama zamanı geciktikçe ve dozlar artııça bitki boyunun kısaldığı gözlemlenmiş olup bulgularımız İçel (2005)'in aspir bitkisinde yaptığı çalışmanın sonucu olarak en yüksek bitki boyunu çıkıştan sonra 4-5 yapraklı devrede, 63.4 $\mathrm{cm}$ ile $6 \mathrm{~g} / \mathrm{da}$ humik asit uygulamasından elde ettiği bulgular ile uyumludur. Day ve ark. (2011) ayçiçeğinde yaptıkları çalışmada en yüksek bitki boyu $133.7 \mathrm{~cm}$ ile sapa kalkma döneminde uygulama yapılan parsellerde ve $6 \mathrm{~g} / \mathrm{da}$ humik asit uygulamasında belirlenirken, en kısa bitki boyunu ise $123.2 \mathrm{~cm}$ ile minyatür tabla oluşum döneminde yapılan uygulamada saptamışlardır.

Ana sapa bağlı yan dal sayısı bakımından ortalama değerleri incelediğimizde; en yüksek değerin 6.80 adet ile sapa kalkma döneminde yapılan $500 \mathrm{ml} / \mathrm{da}$ dozundan, en düşük değerin ise 3.80 adet ile sapa kalkma dönemde yapılan $250 \mathrm{ml} / \mathrm{da}$ uygulamasından elde edildiği görülmektedir. Kolsarıcı ve Er (1988) yaptıkları araştırmalarında kolzada en yüksek ana sapa bağlı yan dal sayısını 6.50 adet olarak saptadıklarını bildirmişlerdir. Bulgularımız araştııııılarınki ile uyumludur.

Çizelge1. Kışlık kolzada farklı humik asit uygulama zamanı ve dozlarının verim ve verim öğelerine etkilerine ilişkin varyans analizi

Table 1. Variance analysis of different doses and durations of humic acid application effects on yield and yield components of winter rapeseed

\begin{tabular}{cccccccc}
\hline V.K. & S.D & Bitki Boyu & $\begin{array}{c}\text { Ana sapa } \\
\text { bağlı yan } \\
\text { dal sayısı }\end{array}$ & $\begin{array}{c}\text { Ana saptaki } \\
\text { kapsül sayısı }\end{array}$ & $\begin{array}{c}\text { Kapsülde } \\
\text { tohum } \\
\text { sayısı }\end{array}$ & $\begin{array}{c}1000 \\
\text { tohum } \\
\text { ağırlı̆ı̆ı }\end{array}$ & $\begin{array}{c}\text { Tohum } \\
\text { verimi }\end{array}$ \\
\hline $\begin{array}{c}\text { Tekerrür } \\
\text { Uygulama }\end{array}$ & 2 & $1.4761^{\text {on }}$ & $1.1996^{\text {on }}$ & $2.0098^{\text {ön }}$ & $1.6290^{\text {ön }}$ & $3.5013^{*}$ & $2.5198^{\text {on }}$ \\
$\begin{array}{c}\text { Zamanı } \\
\text { Uygulama } \\
\text { Dozu }\end{array}$ & 3 & $17.503^{* *}$ & $4.0454^{*}$ & $28.7240^{* *}$ & $9.6715^{* *}$ & $5.0806^{* *}$ & $4.8925^{* *}$ \\
$\begin{array}{c}\text { Uyg.Zam. } \\
\text { *Ug. Doz }\end{array}$ & 9 & $7.437^{* *}$ & $3.8005^{* *}$ & $5.0101^{* *}$ & $5.8558^{* *}$ & $8.5737^{* *}$ & $5.2170^{* *}$ \\
Hata & 30 & 22.120 & 0.693 & 7.105 & 2.026 & 0.064 & 23.785 \\
CV\% & 4.66 & 17.38 & 11.97 & 7.29 & 8.57 & 2.14 \\
\hline
\end{tabular}

*, \% 5 , ** \% 1 düzeyinde öneml

* significant at $\% 5,{ }^{* *}$ significant at $\% 1$ 
Çizelge 2. Kışılık kolzada farklı humik asit uygulama zamanı ve dozlarının verim ve verim öğelerine etkilerine ilişkin ortalamalar ve Duncan gruplandırması

Table 2. Averages and Duncan groups of different doses and durations of humic acid application effects on yield and yield components of winter rapeseed

\begin{tabular}{|c|c|c|c|c|c|}
\hline \multirow{3}{*}{$\begin{array}{l}\text { Uygulama } \\
\text { Zamanları }\end{array}$} & \multicolumn{4}{|c|}{ Uygulama Dozları (ml/da) } & \multirow[b]{3}{*}{ Ortalama } \\
\hline & Kontrol & 250 & 500 & 1000 & \\
\hline & \multicolumn{4}{|c|}{ Bitki Boyu $(\mathrm{cm})$} & \\
\hline Çıkış & $95.53 \mathrm{C}$ & $98.60 \mathrm{C}$ & $98.10 \mathrm{C}$ & $98.77 \mathrm{C}$ & $97.75 \quad \mathrm{~B}$ \\
\hline 6-8 yapraklı & $97.42 \mathrm{C}$ & $118.60 \mathrm{~A}$ & $114.20 \mathrm{AB}$ & $94.70 \mathrm{C}$ & $106.20 \mathrm{~A}$ \\
\hline Sapa kalkma & $94.97 \mathrm{C}$ & $99.67 \quad \mathrm{C}$ & $116.40 \mathrm{AB}$ & $108.80 \mathrm{~B}$ & $104.90 \mathrm{~A}$ \\
\hline Çiçeklenme & $93.93 \mathrm{C}$ & $98.63 \mathrm{C}$ & $91.72 \quad \mathrm{C}$ & $93.37 \quad \mathrm{C}$ & $94.41 \quad \mathrm{~B}$ \\
\hline Ortalama & $95.46 \mathrm{~B}$ & $103.90 \mathrm{~A}$ & $105.10 \quad \mathrm{~A}$ & $98.91 \mathrm{~B}$ & \\
\hline \multicolumn{6}{|l|}{ LSD $0.05=7.843$} \\
\hline \multicolumn{6}{|c|}{ Ana Sapa Bağlı Yan Dal Sayısı (adet) } \\
\hline Çıkış & 4.60 BCD & 4.77 BCD & $4.10 \quad C D$ & 4.33 BCD & $4.45 \mathrm{~B}$ \\
\hline 6-8 yapraklı & 4.43 BCD & 6.53 & $5.67 \mathrm{ABC}$ & $4.30 \mathrm{BCD}$ & $5.23 \mathrm{~A}$ \\
\hline Sapa kalkma & 4.33 BCD & 3.80 & $6.80 \mathrm{~A}$ & $5.77 \mathrm{AB}$ & $5.18 \mathrm{~A}$ \\
\hline Çiçeklenme & $4.03 \mathrm{CD}$ & $4.50 \quad B C D$ & 4.20 BCD & 4.47 BCD & $4.30 \mathrm{~B}$ \\
\hline Ortalama & 4.35 & 4.90 & 5.19 & 4.72 & \\
\hline
\end{tabular}

LSD $0.05=1.388$

\begin{tabular}{|c|c|c|c|c|c|c|c|}
\hline \multicolumn{8}{|c|}{ Ana Saptaki Kapsül Sayısı (adet) } \\
\hline Çıkış & 18.53 & $\mathrm{CDE}$ & 21.13 BCDE & 19.47 BCDE & 21.27 & $\mathrm{BCD}$ & $20.88 \mathrm{~B}$ \\
\hline 6-8 yapraklı & 23.17 & $\mathrm{BC}$ & $28.50 \mathrm{~A}$ & $29.93 \mathrm{~A}$ & 21.33 & BCD & $23.91 \mathrm{~A}$ \\
\hline Sapa kalkma & 23.77 & B & $29.93 \mathrm{~A}$ & $30.77 \mathrm{~A}$ & 18.40 & CDE & $24.76 \mathrm{~A}$ \\
\hline Çiçeklenme & 18.07 & CDE & $16.10 \mathrm{E}$ & 18.87 BCDE & 17.10 & $\mathrm{DE}$ & $19.52 \mathrm{C}$ \\
\hline Ortalama & 19.54 & C & $22.38 \mathrm{~B}$ & $24.76 \mathrm{~A}$ & 22.41 & $\mathrm{~B}$ & \\
\hline
\end{tabular}

LSD $0.05=4.445$

\begin{tabular}{|c|c|c|c|c|c|}
\hline \multicolumn{6}{|c|}{ Kapsülde Tohum Sayısı (adet) } \\
\hline Çıkış & $19.50 \mathrm{BC}$ & $19.63 \mathrm{BC}$ & $19.00 \mathrm{C}$ & $17.93 \mathrm{C}$ & $19.02 \mathrm{~B}$ \\
\hline 6-8 yapraklı & $18.67 \mathrm{C}$ & $22.97 \mathrm{~A}$ & $23.63 \mathrm{~A}$ & $17.50 \mathrm{C}$ & $20.69 \mathrm{~A}$ \\
\hline Sapa kalkma & $18.97 \quad \mathrm{C}$ & $18.40 \quad \mathrm{C}$ & $22.70 \mathrm{~A}$ & $21.67 \mathrm{AB}$ & $20.43 \mathrm{~A}$ \\
\hline Çiçeklenme & $18.03 \mathrm{C}$ & $17.00 \mathrm{C}$ & $17.77 \quad \mathrm{C}$ & $19.03 \mathrm{C}$ & $17.96 \mathrm{~B}$ \\
\hline Ortalama & $18.79 \mathrm{~B}$ & $19.50 \quad \mathrm{~B}$ & $20.77 \mathrm{~A}$ & $19.03 \mathrm{~B}$ & \\
\hline
\end{tabular}

$\underline{\operatorname{LSD}} 0.05=2.373$

\begin{tabular}{|c|c|c|c|c|c|c|c|c|c|}
\hline \multicolumn{10}{|c|}{ Bin Tohum Ağırlığı (g) } \\
\hline Çıkış & 2.61 & $\mathrm{C}$ & 2.65 & C & 3.66 & $A$ & $2.68 \mathrm{BC}$ & 2.20 & $\mathrm{BC}$ \\
\hline $6-8$ yapraklı & 3.68 & A & 2.68 & $B C$ & 3.03 & $B C$ & $3.15 \mathrm{~B}$ & 3.13 & A \\
\hline Sapa kalkma & 2.69 & $B C$ & 2.72 & $B C$ & 2.73 & $B C$ & $2.85 \mathrm{BC}$ & 2.75 & C \\
\hline Çiçeklenme & 3.04 & $\mathrm{BC}$ & 2.78 & BC & 2.55 & C & $3.62 \mathrm{~A}$ & 2.99 & $A B$ \\
\hline Ortalama & 3.00 & A & 2.70 & $B$ & 2.99 & A & $3.08 \mathrm{~A}$ & & \\
\hline
\end{tabular}

$\underline{\operatorname{LSD} 0.05=0.4218}$

\begin{tabular}{|c|c|c|c|c|c|c|}
\hline \multicolumn{7}{|c|}{ Tohum Verimi (kg/da) } \\
\hline Çıkış & 228.3 & BCD & 225.5 CD & 228.3 BCD & 225.3 CD & $226.8 \mathrm{AB}$ \\
\hline 6-8 yapraklı & 224.8 & CD & $238.4 \mathrm{~A}$ & $238.3 \mathrm{~A}$ & 221.2 CD & $230.7 \mathrm{~A}$ \\
\hline Sapa kalkma & 225.1 & CD & $223.1 \mathrm{CD}$ & $237.0 \mathrm{AB}$ & 236.9 AB & $230.5 \mathrm{~A}$ \\
\hline Çiçeklenme & 225.3 & CD & 229.3 BC & $223.5 \mathrm{CD}$ & 218.8 & 224.2 B \\
\hline Ortalama & 225.9 & $B$ & $229.1 \mathrm{AB}$ & $231.8 \mathrm{~A}$ & $225.5 \mathrm{~B}$ & \\
\hline
\end{tabular}


Ana saptaki kapsül sayısı bakımından ortalamalar incelendiğinde; en yüksek değer 30.77 adet ile sapa kalkma döneminde uygulanan $500 \mathrm{ml} / \mathrm{da}$, en düşük değer ise 16.10 adet olarak çiçeklenme döneminde uygulanan $250 \mathrm{ml} / \mathrm{da}$ dozundan elde edilmiştir. Bulgularımız, Bozoğlu ve ark. (2004)'ün Samsun koşullarında bezelye bitkisinde yaptıkları çalışmanın sonucunda humik asidin bitkide bakla sayısını artırdığı yönündeki bulguları ile uyumludur. Araştırmamızda gelişme dönemleri ilerledikçe özellikle çiçeklenme döneminde yapılan humik asit uygulamalarının ana saptaki kapsül sayısının azalmasına neden olduğu gözlemlenmiştir.

Araştırmamızda kapsülde tohum sayısı değeri bakımından ortalamalar 23.63 adet ile en yüksek değeri 6-8 yapraklı dönemde yapılan $500 \mathrm{ml} / \mathrm{da}$ dozunda alırken, en düşük değeri 17.00 adet ile çiçeklenme döneminde yapılan $250 \mathrm{ml} / \mathrm{da}$ dozundan elde edilmiştir. Sonuçlarımız Tunçtürk ve ark. (2005)'in yaptıkları araştırmada tüm çeşitlerin ortalaması olarak ilk yıl 23.2 adet olan kapsüldeki tohum sayısı, ikinci yıl 23.5 adet, üçüncü yıl 22.0 adet olarak tespit ettikleri bulgular ile uyumludur.

Bin tohum ağırlığı bakımından ortalama değerlere baktığımızda en yüksek değer $3.68 \mathrm{~g}$ ile 6-8 yapraklı dönemde ve kontrol uygulamasından elde edilmiştir. En düşük değer ise $2.55 \mathrm{~g}$ ile $500 \mathrm{ml} / \mathrm{da}$ dozunda ve çiçeklenme döneminde yapılan humik asit uygulamalarından elde edilmiştir. Bulgularımız Başalma (2004)'ün yaptığı 2 yıllık çalışmasında birinci yıl $3.87 \mathrm{~g}$, ikinci yıl ise $3.88 \mathrm{~g}$ değerleri ile benzerlik göstermektedir. Ayrıca Tunçtürk ve ark. (2005)'in Van ekolojik koşullarında yaptıkları çalışmadan elde ettikleri en yüksek bin tohum ağırlığı Star (4.05 g) ve Westar (4.04 g) çeşitlerinden, en düşük bin tane ağırlığı ise Tobin ve Kosa $(2.63 \mathrm{~g})$ kolza çeşitlerinden aldıkları bulguları ile benzerlik göstermektedir.

Tohum verimi bakımından en yüksek ortalama değer $238.4 \mathrm{~kg} / \mathrm{da}$ ile $250 \mathrm{ml} / \mathrm{da}$ dozunda, 6-8 yapraklı dönemde elde edilmiştir. En düşük değer ise $218.8 \mathrm{~kg} / \mathrm{da}$ ile çiçeklenme zamanında yapılan $1000 \mathrm{ml} / \mathrm{da}$ uygulamasından alınmıştır. Elde ettiğimiz sonuçlar Başalma (2004)'ün araştırmasında birinci yılda $211.1 \mathrm{~kg} / \mathrm{da}$, ikinci yılda ise ise $216.4 \mathrm{~kg} / \mathrm{da}$ elde ettiği bulgular ile uyumludur. Bayraktar ve ark. (2007) Konya koşullarında kışıı kolzada yaptıkları çalışmalarında en yüksek tohum verim değerini Pactol (211.5 $\mathrm{kg} / \mathrm{da}$ ) ve Bristol (210.3 kg/da) kolza çeşitlerinden aldıklarını bildirmişlerdir.

\section{Sonuç}

Verim ve verim öğeleri bakımından kışlık kolzanın yazlık kolzaya nazaran daha verimli ve avantajlı olduğu bilinmektedir. Günümüzde uygulanan yetiştirme teknikleri ve organik gübrelemeler ile kolzanın verim potansiyeli arttırımaya çalışılmaktadır. Hümik asit kullanımı ile hem toprak koşulları iyileştirilmekte hem de bitkilerin hastalık ve zararılıara dayanıkııı̆ı artııımaktadır. Bu araştırmadan elde ettiğimiz bulgulara göre kışlık kolza çeşidi olan Bristol'e uyguladığımız 250- $500 \mathrm{ml} / \mathrm{da}$ humik asit dozunun, uygulama zamanlarından ise 6-8 yapraklı dönem ve sapa kalkma döneminde humik asit uygulamalarının verime olumlu etkisinin olduğu söylenebilir.

\section{Kaynaklar}

Anğın N., Vurarak Y., 2012. Çukurova bölgesine uygun kolza (Brassica napus L.) çeşitlerinin belirlenmesi. Tarım Bilimleri Araştırma Dergisi 5 (1): 90-92, ISSN: 1308-3945, E-ISSN: 1308-027X, www.nobel.gen.tr

Anonim 2015. TÜİK verileri (Erişim tarihi:08/10/2015).

Asri Ö.F., Demirtaş E.I., Özkan C.F., Arı N., 2011. Organik ve kimyasal gübre uygulamalarının hıyar bitkisinin verim, kalite ve mineral içeriklerine etkileri, Akdeniz Üniversitesi Ziraat Fakültesi Dergisi. 24(2): 139-143

Başalma D., 2004. Kışlık kolza (Brassica napus ssp. oleifera L.) Çeşitlerinin ankara koşullarında verim ve verim öğeleri yönünden karşılaştırılması. Tarım Bilimleri Dergisi. 10(2): 211-217

Bayraktar N., Öztürk Ö., Mert M., 2007. Konya Koşullarında Bazı Kışıık Kolza (Brassica napus L.) Çeşitlerinin Verim ve Verim Öğelerinin Belirlenmesi, 7. Tarla Bitkileri Kongresi, 25-27 Haziran Erzurum, 747-750

Beğbağa M., Öztürk Ö., 2008. Ege bölgesi koşullarında bazı kışlık kolza (Brassica napus ssp. oleifera) çeşitlerinde farklı ekim zamanı uygulamalarının verim, verim unsurları ve kalite üzerine etkileri, Selçuk Üniversitesi Ziraat Fakültesi Dergisi, 22 (44): 84-98

Bozoğlu H., Peşken E., Gülümser A., 2004. Sıra aralığı ve potasyum humat uygulamasının bezelyenin verim ve bazı özelliklerine etkisi. Tarım Bilimleri Dergisi. 10 (1) 53-58. Ankara

Day S., Kolsarıcı Ö., Kaya M.D., 2011. Humik asit uygulama zamanı ve dozlarının ayçiçeğinde (Helianthus annuus) verim, verim öğeleri ve yağ oranına etkisi, Akdeniz Üniversitesi Ziraat Fakültesi Dergisi (2011) 24(1):33-37 
Düzgüneş O., Kesici T., Kavuncu O., Gürbüz F., 1987. Araştırma ve Deneme Metotları. Ankara Üniversitesi, Ziraat Fakültesi Yayınları No: 1021, 229 s., Ankara

Ergönül U., 2011. Ayçiçeği (Helianthus annuus L.) Çeşitlerine Uygulanan Hümik Asit ve Leonardit'in Verim ve Verim Öğeleri Üzerine Etkileri, Ankara Üniversitesi Fen Bilimleri Enstitüsü Yüksek Lisans Tezi (Basılmamış), 62 sayfa

İçel C.D., 2005. Humik Asit Uygulama Zamanı ve Dozlarının Aspir (Carthamus tinctorius L.)'de Verim, Verim Öğeleri ve Yağ Oranına Etkisi Ankara Üniversitesi Fen Bilimleri Enstitüsü Yüksek Lisans Tezi (Basılmamış), 70 sayfa

Karaman M.R., Şahin S., Geboloğlu N., Turan M., Güneş A., Tutar A., 2012. Humik Asit Uygulaması Altında Farklı Domates Çeşitlerinin (Lycopersicon esculentum L.) Demir Alım Etkinlikleri. SAÜ Fen Edebiyat Dergisi (2012-1) 301-308
Kolsarıcı Ö., Er C., 1988. Researches on the Determination of the most suitable sowing time, variety and plant density in oilseed rape cultivation in Amasya. Turkish Journal of Agricultural and Forestry, Vol.12, Num:2, 163177

Sözüdoğru S., Kütük A.C., Yalçın R., Usta S.. 1996. Hümik asidin fasulye bitkisinin gelişimi ve besin maddeleri alımı üzerine etkisi. ankara üniversitesi Ziraat Fakültesi Yayın No: 1452, Bilimsel Araştırma ve İncelemeler: 800, Ankara

Tunçtürk M., Yılmaz İ., Erman M., Tunçtürk R., 2005. Yazlık kolza (Brassica napus ssp. oleifera L.) çeşitlerinin van ekolojik koşullarında verim ve verim özellikleri yönünden karşılaştırılması, Tarım Bilimleri Dergisi, 11:(1) 78-85 